\title{
Black Esophagus with Acute Aortic Dissection
}

\author{
Yu Horiuchi ${ }^{1}$, Nobuo Toda ${ }^{2}$ and Kengo Tanabe ${ }^{1}$
}

Key words: Black esophagus, Acute esophageal necrosis, Aortic dissection

\author{
(Intern Med Advance Publication) \\ (DOI: 10.2169/internalmedicine.8121-21)
}
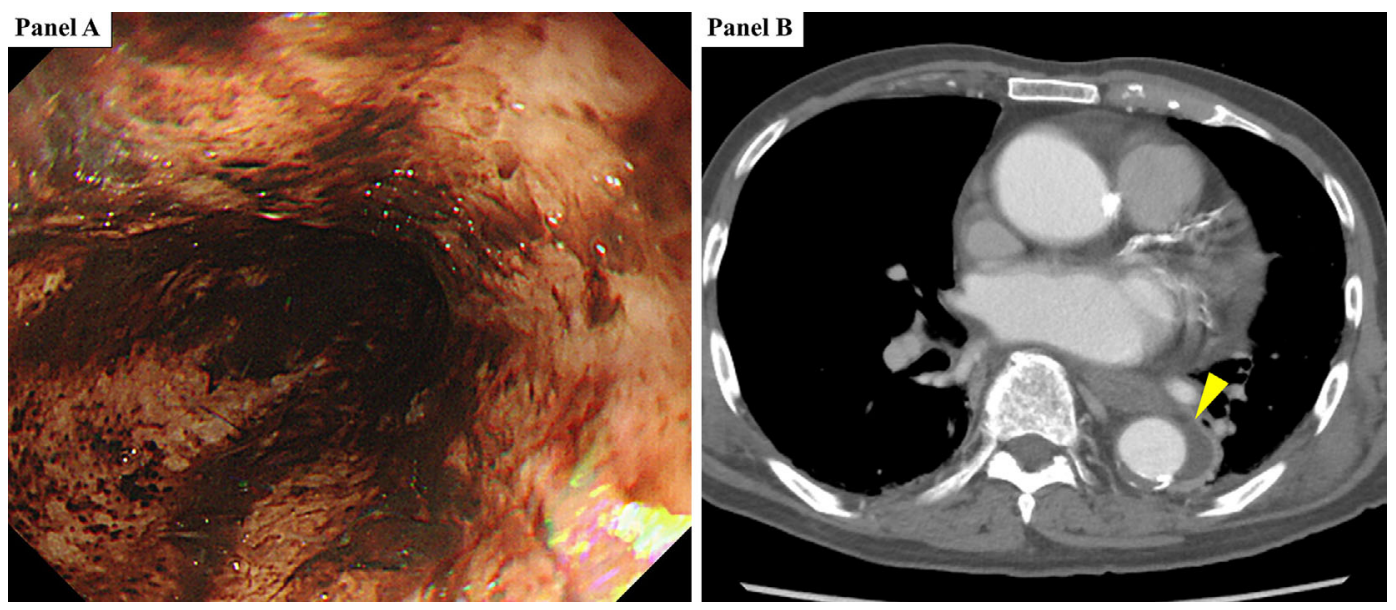

Picture.

An 87-year-old man presented to the emergency department with hematemesis and back pain with grade III hypertension. Esophagogastroduodenoscopy revealed a black esophagus, indicating acute esophageal necrosis (AEN) with diffuse black mucosal discoloration (Panel A). AEN can be caused by impaired esophageal circulation, especially in the hypovascular distal third area, with a general state of debilitation resulting in weakened mucous defense mechanisms (1). In the present case, the cause of esophageal malperfusion was investigated by contrast-enhanced computed tomography, and DeBakey type IIIa aortic dissection was diagnosed (Panel B). Thrombotic occlusion of the false lumen may have impaired the blood flow to the intercostal arteries and esophageal perfusion. Following treatment with antihypertensive therapy and a proton-pump inhibitor, esophagogastroduodenoscopy revealed the resolution of
AEN. The patient was discharged with no complications. The prompt identification of aortic dissection and appropriate blood pressure control may have led to a favorable outcome.

The authors state that they have no Conflict of Interest (COI).

\section{Reference}

1. Dias E, Santos-Antunes J, Macedo G. Diagnosis and management of acute esophageal necrosis. Ann Gastroenterol 32 (6): 529-540, 2019.

The Internal Medicine is an Open Access journal distributed under the Creative Commons Attribution-NonCommercial-NoDerivatives 4.0 International License. To view the details of this license, please visit (https://creativecommons.org/licenses/ by-nc-nd/4.0/).

${ }^{1}$ Division of Cardiology, Mitsui Memorial Hospital, Japan and ${ }^{2}$ Department of Gastroenterology, Mitsui Memorial Hospital, Japan Received: June 13, 2021; Accepted: August 4, 2021; Advance Publication by J-STAGE: September 18, 2021

Correspondence to Dr. Kengo Tanabe, kengo-t@ zd5.so-net.ne.jp

(C) The Japanese Society of Internal Medicine. Intern Med Advance Publication 